\title{
Haemolytic-uraemic syndrome: an analysis of prognostic features
}

\author{
R S TROMPETER, R SCHWARTZ, C CHANTLER, M J DILLON, G B HAYCOCK, \\ R KAY, AND T M BARRATT
}

Department of Nephrology, Institute of Child Health, London; Evelina Children's Department, Guy's Hospital, London; Department of Probability and Statistics, University of Sheffield

SUMMARY Seventy-two children with the haemolytic-uraemic syndrome were seen between 1969 and 1980 at The Hospital for Sick Children and Guy's Hospital, London. They probably constitute the majority of such cases in south-east England during that period. Boys and girls were affected equally, the mean age at presentation was $3 \cdot 5$ years, and a peak incidence of the disorder in summer months was observed. In $52(72 \%)$ there was a history of diarrhoea at onset. Fifty-seven ( $78 \%$ ) were managed by dialysis. Fifty $(70 \%)$ of the 72 children had a favourable outcome with complete recovery, $3(4 \%)$ died in the acute phase of the illness, $8(11 \%)$ had residual hypertension or chronic renal failure, and $11(16 \%)$ never recovered renal function. The probability of complete recovery of renal function was analysed by logistic regression which indicated that younger age, presentation in the summer months, diarrhoea at onset and, in those patients who were dialysed, a short prodromal illness were associated with a good outcome. Further analysis of the interaction among these variables in the patient group as a whole indicated that diarrhoea favoured a good outcome among boys but not girls.

In 1955 Gasser et al. described the association of an acute haemolytic anaemia, thrombocytopenia, and renal failure. ${ }^{1}$ The disorder is now known as the haemolytic-uraemic syndrome (HUS), and is recognised as a major cause of acute renal failure in children. It is more common under age 4 years, and is often associated with a history of diarrhoea or upper respiratory tract infection. ${ }^{2-7}$ There appear to be endemic areas-such as Argentina ${ }^{6}$ and the Netherlands ${ }^{7}$-and elsewhere the disorder often occurs in mini-epidemics. It is known that although most affected children recover a few do not, and this heterogeneity of outcome is a major complicating factor in the analysis of results of treatment or the design of prospective therapeutic trials.

In a previous analysis of 34 cases in England, a poor outcome was associated with persistent anaemia, hepatosplenomegaly, purpura, and the absence of antecedent diarrhoea. ${ }^{8}$ In order to analyse the natural history and predictive variables of the disorder as seen in children resident in south-east England, we have reviewed the case records of all the 72 such children admitted to the two renal units in London responsible for the care of most children with acute renal failure in the area.

\section{Patients and methods}

HUS was diagnosed in children with renal failure, a haemolytic anaemia with fragmented cells and thrombocytopenia in whom other causes, particularly septicaemia, had been excluded. The records of the 72 such children admitted to The Hospital for Sick Children or Guy's Hospital from January 1969 to December 1980 were reviewed: patients who developed the disorder abroad were excluded. Details of any prodromal illness were noted, and its duration calculated as the interval between the first symptom of the illness and the onset of dialysis; thus these data refer only to dialysed patients. Cases were classified as 'epidemic' if there were 2 others presenting within the same or adjacent months.

\section{Classification of outcome.}

\section{Group 1}

Healthy, with normal blood pressure, normal renal function and urinary sediment, or with minor abnormalities in urinary sediment only.

\section{Group 2}

Major abnormalities of urinary deposit, proteinuria 
(2+ or more on Albustix) or hypertension, but otherwise normal renal function.

\section{Group 3}

Chronic renal failure (glomerular filtration rate $<40 \mathrm{ml} / \mathrm{min}$ per $1.73 \mathrm{~m}^{2}$ surface area, or plasma creatinine concentration $>100 \mu \mathrm{mol} / 1(1 \cdot 1 \mathrm{mg} / 100$ $\mathrm{ml})$.

\section{Group 4}

End-stage renal failure on regular dialysis or with a functioning renal graft.

\section{Group 5}

Late death from renal failure.

\section{Group 6}

Early death in the acute phase of the illness before outcome of renal function could be assessed.

In the analysis of results we have classified group 1 as having a favourable outcome, groups $2-5$ as unfavourable, and omitted group 6 as not contributing data to the long-term prognosis.

Candidate predictive variables were analysed by logistic regression which models the logarithm of the odds of a good outcome as a linear function of the independent variables under consideration. ${ }^{9}$ If $P$ denotes a child's probability of a good outcome then, (1-P) is the probability of a poor outcome and $(\mathrm{P} / 1-\mathrm{P})$ are the odds in favour of 'good'; the model assumes $(P / 1-P)=\exp \left(\beta_{0}+\beta_{1} x_{1}+\ldots \beta_{R} x_{R}\right)$ where $x_{1}, x_{2}, \ldots . x_{R}$ are the child's values of the independent variables. The equation transforms to $\ln (\mathbf{P} / 1-\mathrm{P})=\beta_{0}+\beta_{1} \mathbf{x}_{1}+\ldots \beta_{R} \mathbf{x}_{R}$ and the analysis provides estimates of $\beta_{0}, \beta_{1}, \ldots \beta_{R}$, which can be used to evaluate the effect and significance of the $x$ variables. The set of values of $x_{1} \ldots . x_{R}$ for an individual child can be inserted into the equation and, using the estimated values of $\beta_{0}, \beta_{1} \ldots \beta_{R}$, a value of 1 n (P/1-P) can be obtained which can then be used as a score to allocate the child to a 'good outcome predicted' or 'poor outcome predicted' group, depending on whether $1 \mathrm{n}(\mathbf{P} / 1-\mathrm{P})$ is greater or less than zero.

\section{Results}

Patients. There were 35 boys and 37 girls. Their mean age was $3 \cdot 5$ years; $21(29 \%)$ were under 1 year and $24(33 \%)$ over 4 years of age (Fig. 1). In some years $(1969,1979)$ only one patient was seen, but in 1980 there were 19 patients. Forty-nine $(68 \%)$ presented in the summer months (May-September inclusive; $\left.\chi^{2}=22 ; \quad P<0.01\right)$, with a peak in September (Fig. 2). Only 6 of the children lived in

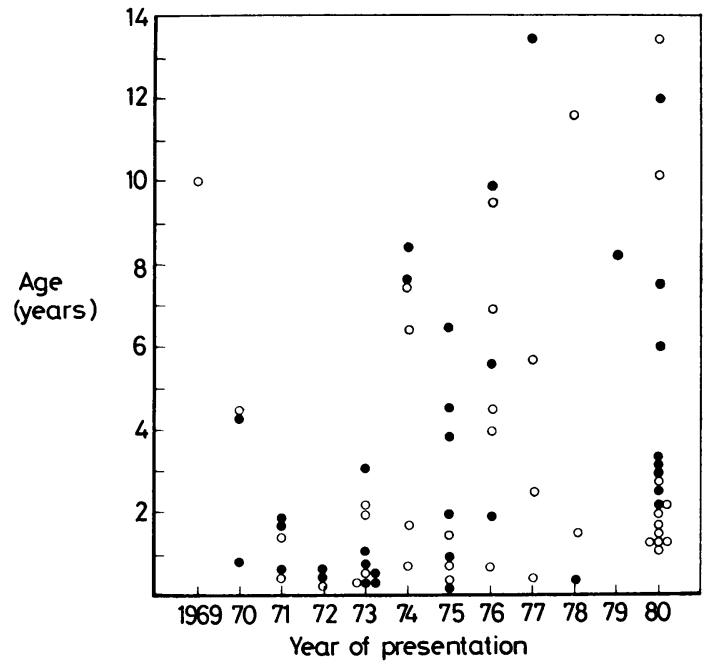

Fig. 1 Age, gender, and year of presentation of 72 children with HUS $1969-80 . \bullet=$ boys, $\mathrm{O}=$ girls.

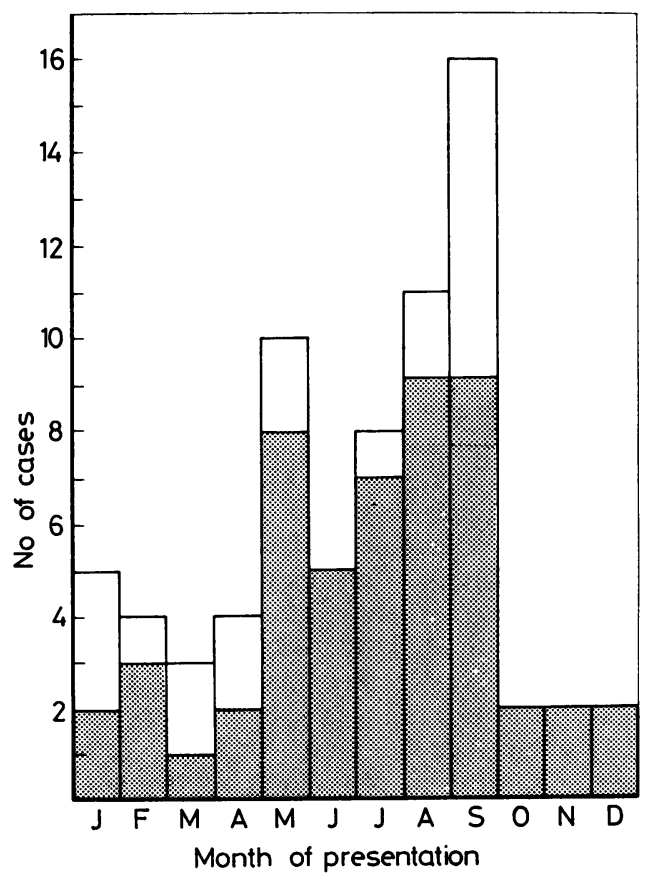

Fig. 2 Season of presentation. $\square=$ diarrhoea, $\square=$ no diarrhoea 
the London metropolitan area, the majority coming from outer suburban or rural regions of south-east England. On child had a sibling similarly affected with HUS who died before admission to hospital. In $52(72 \%)$ there was a history of diarrhoea at onset and in $9(13 \%)$ there was respiratory tract disease initially. There was no association between diarrhoea and season (Fig. 2). There were no differences in age and gender distribution or in the incidence of diarrhoea between the 28 affected children who presented in the first 6 years (1969-74) of the study and later cases.

Fifty-seven ( $78 \%$ ) of the children were treated by peritoneal or haemodialysis or both, and in them the duration of the prodrome ranged from 1 to 60 days, averaging 11.3 days. In the earlier years, up to 1975 , most patients were heparinised but in the second half of the series only a few have been, and between 1975 and 1977 some patients received fibrinolytic therapy. ${ }^{10}$ In addition, most patients received blood transfusion, recently with donor-fresh blood and sometimes with fresh frozen plasma or plasmapheresis' as well.

Outcome. Fifty $(70 \%)$ of the children had a good outcome with complete recovery (group 1), including all but one of the 15 undialysed patients. Two patients have residual proteinuria and hypertension (group 2), 6 have chronic renal failure (group 3), 3 are on renal replacement programmes (group 4), and 8 died

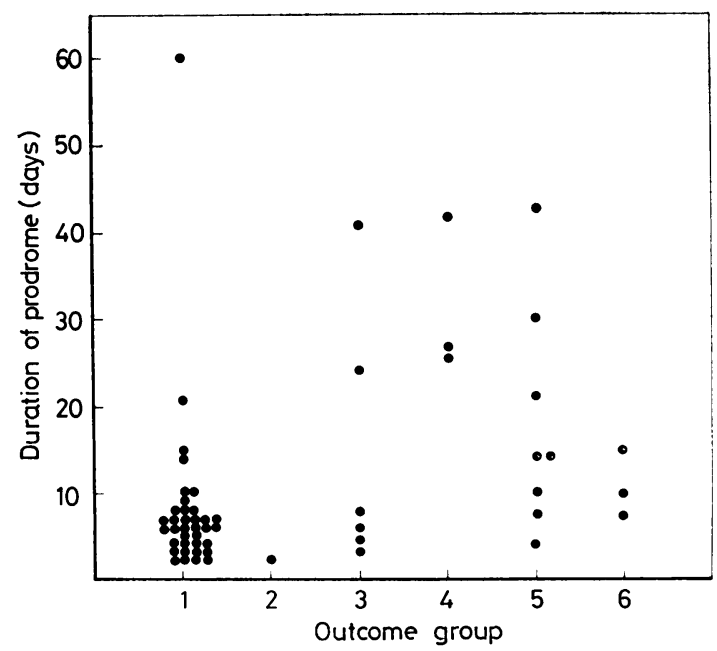

Fig. 3 Duration of prodromal illness in the 56 dialysed patients. Outcome groups: $1=$ complete recovery, $2=$ residual hypertension/proteinuria, $3=$ chronic renal failure, $4=$ dialysis/transplant, $5=$ late death, $6=$ early death. without recovery of renal function (group 5): in all $19(26 \%)$ are classified as having a poor outcome. Three patients died during the first days of admission and thus outcome cannot be evaluated (group 6) (Fig. 3).

Thirty-seven $(66 \%)$ of the 57 dialysed patients recovered sufficient renal function to stop dialysis within 2 weeks and only one of these had residual nephropathy; 3 died during this period. By the end of 4 weeks, 2 more had recovered (one completely), and by the end of 8 weeks a further 3 died without recovering renal function and in an additional patient dialysis was stopped after 7 weeks, and although renal function was very poor he survived a further 8 months: he has been assigned to group 5 . Of the remaining 11 cases still on dialysis at 8 weeks, 4 subsequently recovered renal function after 10 weeks ( 2 patients), 14 and 52 weeks respectively, but all had residual nephropathy, 4 died, and 3 are alive on regular dialysis or have a functioning graft. Thus only one of 37 cases dialysed for less than 2 weeks had a poor outcome, whereas only one of 16 cases dialysed for more than 2 weeks had complete recovery of function. None of the children with favourable outcome subsequently deteriorated to groups 2-5.

Eight $(29 \%)$ of the 28 children seen in the first 6 years of the survey (when most patients were heparinised) had a poor outcome, not significantly different from the $17(40 \%)$ of the 43 children in the second 6-year period, when only a few patients were heparinised.

Eight $(80 \%)$ of the 10 dialysed patients who had a prodromal illness of more than 20 days failed to recover function completely, in contrast to only 14 $(30 \%)$ of the 47 with a prodrome less than 20 days $\left(x^{2}=8.5 ; P<0.01\right)$ (Fig. 3).

Prognostic variables. The probability of a good outcome (group 1) as opposed to a poor outcome (groups 2-5) was analysed by logistic regression. The prognostic variables considered were (1) age, (2) gender, (3) season, (4) epidemicity, and (5) a prodrome of diarrhoea.

A first analysis of the 69 cases (excluding group 6) indicated that age $(P<0.05)$ and season $(P<0.01)$ had a significant effect on outcome, diarrhoea a marginal one $(P \bumpeq 0 \cdot 1)$, but gender and epidemicity did not: thus older children did worse, whereas summer cases and children with diarrhoea did better.

Inclusion of the duration of prodrome and omission of gender and epidemicity in similar analysis restricted to the 54 dialysed patients (excluding those in group 6) showed the duration of prodrome to be a significant variable $(P<0.05)$ and strengthened the effect of diarrhoea $(P<0.05)$ with 
the other variables retaining effects similar in magnitude and direction as in the full group: of the patients dialysed, those with a long prodrome did worse.

Investigation of the possible interaction of the predictive variables in the group as a whole showed that the only terms to have a significant interaction were gender and diarrhoea: it was only in boys that the presence of diarrhoea was associated with an increased probability of a good outcome.

The probability of $\mathbf{P}$ at presentation of a good outcome is given by $\ln (\mathrm{P} / 1-\mathrm{P})=\beta_{0}+\beta_{1} \mathrm{x}_{1}+\beta_{2} \mathrm{x}_{2}$ $+\beta_{3} x_{3}+\beta_{5} x_{5}+\beta_{25} x_{25}$ where $x_{1}=$ age (years), $x_{2}=$ gender $($ female $=0$, male $=1), x_{3}=$ season (winter $=0$, summer $=1$ ), $x_{5}=$ diarrhoea (absent $=0$, present $=1$ ), and $x_{25}$ represents the interaction of gender and diarrhoea taking a value of 1 in boys with diarrhoea and 0 in all other cases. The estimates for the coefficients $\beta$ ( \pm standard errors) were $\beta_{0}=1.66, \beta_{1}$ (age) $=-0.27 \pm 0 \cdot 11, \beta_{2}$ (gender) $=$ $-2.78 \pm 1.49, \beta_{3}$ (season) $=2.60 \pm 0.82, \beta_{5}$ $($ diarrhoea $)=-1.43( \pm 1.41)$, and $\beta_{25}$ (gender + diarrhoea) $=4.49 \pm 1 \cdot 85$. The relationship between $P$ and $\ln (\mathbf{P} / 1-P)$ is evident in Fig. 4. This analysis

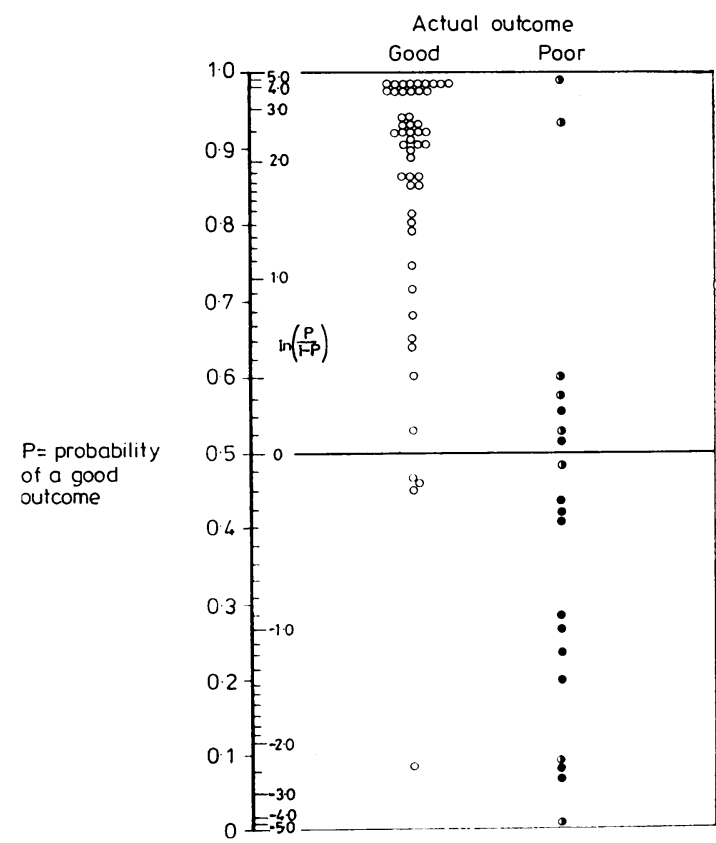

Fig. 4 Probability of good outcome, calculated from age, gender, season, and presence of diarrhoea at onset. $\mathrm{O}=$ complete recovery (group 1$),(=$ residual nephropathy (groups 2 and 3), $\bullet=$ no recovery of renal function (groups 4 and 5). correctly predicted $84 \%$ of the outcomes and identified $63 \%$ of the unfavourable results (Fig. 4).

\section{Discussion}

The clinical features of HUS are well known, and the children in this series conform to the expected pattern. However, in some other series the mean age at the age of onset was about one year, whereas in the present series it was 3.4 years. The asssociation with diarrhoea is usual, and the seasonal variation in incidence is in accord with other reports 71112 showing a peak in the spring and summer months.

The outcome, with $11 \%$ having residual nephropathy and $15 \%$ failing to recover renal function, also accords with experience in non-endemic areas. ${ }^{13}$ In this retrospective survey of 12 years' experience in two separate paediatric nephrology departments it was considered that the criteria for selecting patients for treatment-for example heparinisation and the regimens followed-were too varied for detailed analysis, but no trends were observed.

Our data provide a basis for prognosis at 3 moments in the illness. Firstly, at presentation, youth, the presence of diarrhoea, and occurrence in summer months have been identified as good prognostic features. The appreciation of the interaction effect that the association of diarrhoea with a good outcome is confined to boys necessitates a rather more complicated formula for calculation of the probability of a good outcome correctly predicted and $63 \%$ of poor outcomes identified (Fig. 4).

Secondly, at the onset of dialysis, the effect of the duration of prodromal illness is introduced (Fig. 3). The association of long prodrome with poor outcome has several possible interpretations: it may be that early dialysis improves the outcome of the renal disease, or that variable indications for dialysis in the group as a whole lead to the inclusion of patients who would have fared well anyway in the early dialysed group, or that an explosive onset is more likely to necessitate blood transfusion which may itself have a beneficial effect, or that the nature of the prodromal illness is different in patients with a poor outcome. Of this possibilities, we favour the last, for we have already identified another feature of the prodromal illness-that is the presence or absence of diarrhoea-as influencing outcome.

Thirdly, the watershed on dialysis appears to be at 2 weeks, for of the 37 children who came off dialysis before, only one had residual nephropathy, whereas of those 16 needing dialysis longer only one recovered completely. It is worthy of note that one child was able to come off dialysis after one year of treatment, and 3 children remained anuric for more than 10 
weeks before good, albeit incomplete, recovery of function; several months' dialysis must be undertaken before irreversibility can be assumed and, for example, bilateral nephrectomy undertaken. ${ }^{14}$

Fig. 4 shows that the patients who have an incomplete recovery (groups 2 and 3 ) have clinical features more closely resembling those of the patients who recover completely (group 1) than those who do not recover at all (groups 4 and 5).

The introduction of new concepts in the pathogenesis of HUS $^{15}$ has stimulated other approaches to treatment-for example, replacement of apparently deficient plasma factors with the infusion of donor-fresh plasma or plasmapheresis. It is worth noting that if a controlled trial of a new treatment were planned in which it was desired to detect, with a confidence of 0.95 in a 2-sided test and with a power of 0.90 , a reduction by half in the proportion of poor outcomes from 0.26 to $0 \cdot 13$, it would be necessary to enter 350 patients into the trial. ${ }^{16}$ Some criteria for selection of poor risk patients are therefore essential in future therapeutic studies, and new treatments will need evaluation by controlled trial in groups of patients with a poor outcome predicted on some such criteria as presented in this paper, both for reasons of statistical economy, and to avoid the administration of potentially injurious forms of treatment to patients likely to have a good outcome in any case.

It is clear that HUS is a heterogeneous condition, and our data are compatible with the hypothesis, already proposed on the basis of family studies, ${ }^{17}$ that there are two subsets in children, the one being more common in younger children, in summer months, and in epidemic areas, having an explosive onset associated with diarrhoea but having an essentially good prognosis, whereas the other occurs sporadically in older children with more gradual onset, sometimes with a respiratory rather than a gastrointestinal prodrome, and carries a worse prognosis for renal function. Investigations both of pathogenesis ${ }^{15}$ and treatment must recognise this heterogeneity.

\section{References}

1 Gasser C, Gautier E, Steck A, Siebenmann R E, Oechslin R. Hämolytisch-urämische syndrome. Bilaterale nierenrindennekrosen bei akuten erwobenen hämolyti- schen anämeen. Schweiz Med Wochenschr 1955; 85: 905-9.

2 Gianantonio C A, Vitacco M, Mendilaharzu F, Rutty A, Mendilaharzu J. The hemolytic-uremic syndrome. J Pediatr 1964; 64: 478-91.

3 Gianantonio C, Vitacco M, Mendilaharzu F, Gallo G E. The hemolytic-uremic syndrome. Renal status of 76 patients at long-term follow-up. $J$ Pediatr 1968; 72: 757-65.

4 Kaplan B S, Katz J, Krawitz S, Lurie A E. An analysis of the results of therapy in 67 cases of the hemolyticuramic syndrome. J Pediatr 1971; 78: 420-5.

5 Lieberman E. Hemolytic-uremic syndrome. $J$ Pediatr 1972;80: 1-16.

6 Gianantonio C A, Vitacco M, Mendilaharzu F, Gallo G E, Sojo E T. The hemolytic-uremic syndrome. Nephror. 1973; 11: 174-92.

7 van Wierengen $\mathbf{P}$ M V, Monnens L A $\mathbf{H}$, Schretlen E D A M. Haemolytic-uraemic syndrome. Epidemiological and clinical study. Arch Dis Child 1974; 49: 432-7.

8 Stuart J, Winterborn M H, White R H R, Flinn R M. Thrombolytic therapy in the haemolytic-uraemic syndrome. Br Med J 1974; iii: 217-21.

9 Anderson J A. Logistic discrimination. In: Krishnaiah P R, ed. Handbook of statistics. Vol. 2. New York: North Holland, 1980.

10 Jones R W A, Morris M C, Maisey M N, Saxton H M, Chantler C. Endarterial urokinase in childhood hemolytic-uremic syndrome. Kidney Int 1981; 20: 723-7.

11 McLean M M, Hilton Jones C, Sutherland D A. Haemolytic-uraemic syndrome. A report of an outbreak. Arch Dis Child 1966; 41: 76-81.

12 Sorrenti L Y, Lewy P R. The hemolytic-uremic syndrome. Experience at a centre in the Midwest. Am J Dis Child $1978 ; 132$ : 59-62.

13 Habib R, Courtecuisse V, Leclerc F, Mathieu H, Royer P. Etude anatamopathologique de 35 observations de syndrome hémolitique et urémique de l'enfant. Arch Fr Pediatr 1969; 26: 391-416.

14 Sharpstone P, Evans R G, O'Shea M, Alexander L, Lee H A. Haemolytic-uraemic syndrome: survival after prolonged oliguria. Arch Dis Child 1968; 43: 711-6.

15 Remuzzi G, Misiani R, Marchesi D, et al. Haemolyticuraemic syndrome: deficiency of plasma factor(s) regulating prostacyclin activity? Lancet 1978 ; ii: 871-2.

16 Boag J W, Haybittle J L, Fowler J F, Emery E W. The number of patients required in a clinical trial. Br $\mathrm{J}$ Radiol $1971 ; 44: 122-5$.

17 Kaplan B S, Chesney R W, Drummond K N. Hemolytic-uremic syndrome in families. $N$ Engl J Med 1975 292: $1090-3$.

Correspondence to Professor T M Barratt, Department of Paediatric Nephrology, Institute of Child Health, 30 Guilford Street, London WC1N 1EH.

Received 8 October 1982 